\title{
Geomorphological hazard and tourist vulnerability along Portofino Park trails (Italy)
}

\author{
P. Brandolini ${ }^{1}$, F. Faccini ${ }^{1}$, and M. Piccazzo ${ }^{2}$ \\ ${ }^{1}$ DISAM Department, University of Genoa, Italy \\ ${ }^{2}$ DIPTERIS Department, University of Genoa, Italy
}

Received: 26 July 2005 - Revised: 7 April 2006 - Accepted: 7 April 2006 - Published: 27 June 2006

\begin{abstract}
The many trails existing in the coastal area of Portofino Promontory are used by tourists for trekking or as pathways to small villages and beaches. The aim of this paper is to define geomorphological hazard and tourist vulnerability in this area, within the framework of the management and planning of hiking activities in Portofino Natural Park.

In particular, processes triggered by gravity, running waters and wave motion, affecting the slopes and the cliff, are considered. The typology of the trails and trail maintenance are also taken into account in relation to weather conditions that can make the excursion routes dangerous for tourists.

In conclusion, an operative model is applied for the definition of possible risk scenarios. This model is founded on an inventory and the quantification of geomorphological hazards and tourist vulnerability, in comparison with trail rescue data. The model can be applied to other environments and tourist areas.
\end{abstract}

\section{Introduction}

Research focused on geomorphological hazard associated with tourist activities and facilities is currently taking on great importance because of hazard-related environmental and socioeconomic ramifications. This trend is particularly pertinent in the case of vast areas of the Alpine and Mediterranean regions.

Tourism has led to the occupation and utilisation of areas marked by ever-increasing geomorphological fragility. There has been an enormous increase in the number of visitors - visitors who are often inadequately prepared (in terms of skills, experience and equipment) - to areas considered virtually inaccessible just a few decades ago, in both high mountain and coastal sectors (Dowling and Newsome, 2005;

Correspondence to: P. Brandolini

(brando@unige.it)
Swarbrooke et al., 2003). This phenomenon has led to increased risk and environmental impact, as in the case of Portofino Natural Park in the northwestern coastal sector of Italy; Portofino is an Italian seaside tourist resort of international renown.

The boom in hiking and related tourist activities along the steep slopes of the promontory, which are frequently affected by instability phenomena, has brought about an increase in accidents involving visitors to the area. Data collected by the C.N.S.A.S. (National Alpine and Speleological Rescue Corps) on rescue operations performed in a recent five-year period (1999-2004) on the park trails, show an average of 5-6 major rescue efforts per year, involving a total of 28 persons.

Taking the concept of risk (Varnes, 1984; Panizza, 1987; Bell, 1999; Grecu et al., 2003; Glade et al., 2005) as the starting point and defining it as a product of hazard and vulnerability, an operative model has been applied for the assessment of possible risk scenarios, and tested in several morphoclimatic environments within the framework of the Ministry of Education, University and Research project "Geomorphological heritage as a resource for sustainable tourism" (Brandolini et al., 2004a, b). This model analyzes geomorphological instability phenomena, together with the structural features characterizing the trails. In the case of particular meteorological conditions (e.g. heavy rainfall, high temperatures, winds), the latter can contribute to increasing the risk of accidents, as can the level of physical fitness and the technical skills of visitors.

The aim of this study is to improve the above-mentioned model, in order to make it applicable to a larger number of morphodynamic environments and tourist areas. Greater knowledge about the geomorphological hazards associated with hiking and trekking activities can contribute to making tourists more aware of natural phenomena and risky situations (Solana and Kilburn, 2003).

Published by Copernicus GmbH on behalf of the European Geosciences Union. 


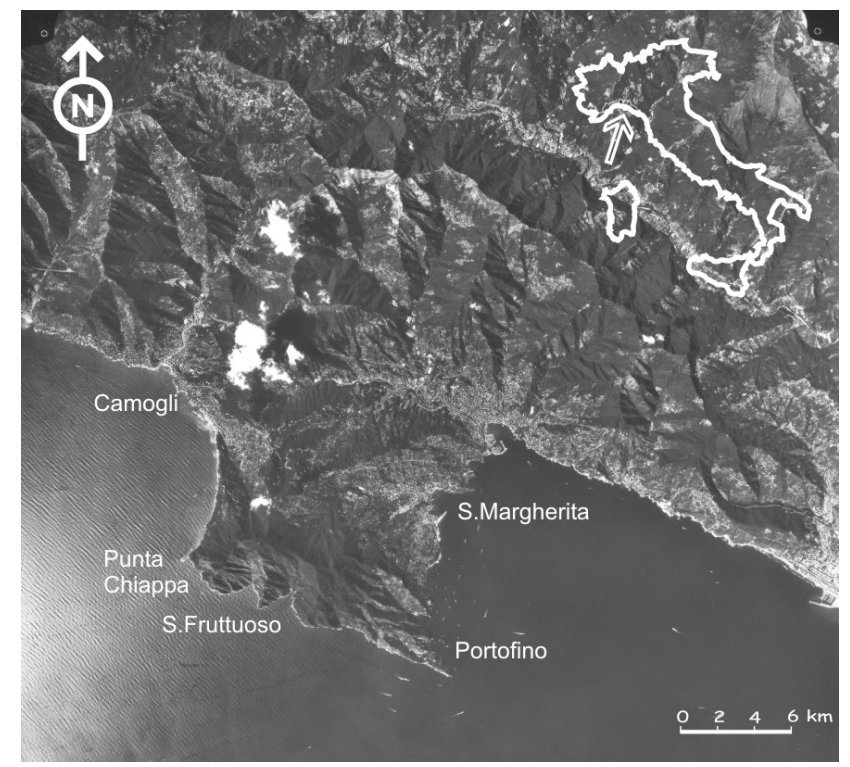

Fig. 1. Location of the study area. High-altitude $(12500 \mathrm{~m})$ aerial photograph of the Promontory of Portofino (Flight Italia 94 - Consorzio Compagnie Aeronautiche, Parma).

\section{General framework}

Situated about $25 \mathrm{~km}$ E of Genoa, the Portofino Promontory abruptly breaks up the continuity of the coastline between Genoa and Sestri Levante and covers a surface area of about $18 \mathrm{~km}^{2}$. It was declared a protected area in 1935 .

The promontory is a massive and prominent SSW projection clearly differentiating the virtually rectilinear pattern of the surrounding coastline (Fig. 1). Considerable variability of the morphology can be observed on the western side, where the promontory extends in a N-S direction and is almost rectilinear between Camogli and Punta Chiappa for about $3 \mathrm{~km}$. The eastern side is virtually parallel to the western side, with a heightened complexity and a coastal extension of about $8 \mathrm{~km}$. The inlets of Cala dell'Oro and San Fruttuoso are located on the southern side, which presents a general E-W orientation and extends for a length of about $6.5 \mathrm{~km}$.

Mt. Portofino (610 $\mathrm{m}$ a.s.l.) is the highest orographic elevation on the promontory. It stands on the divide that is subparallel to the southern shoreline, where several smaller peaks are observable, among which Mt. Tocco (543 m a.s.1.), Mt. delle Bocche (506 m a.s.1.) and Mt. Pollone ( $465 \mathrm{~m}$ a.s.l.).

The climate of the promontory is conditioned by the morphology, so that it can be subdivided into two zones: a) a typically Mediterranean one on the southern slope, with dry, warm summers and mild winters; b) a mid-hill zone on the northern slope, with lower mean winter temperatures and higher rainfall, especially in the sectors exposed to the $\mathrm{N}$.

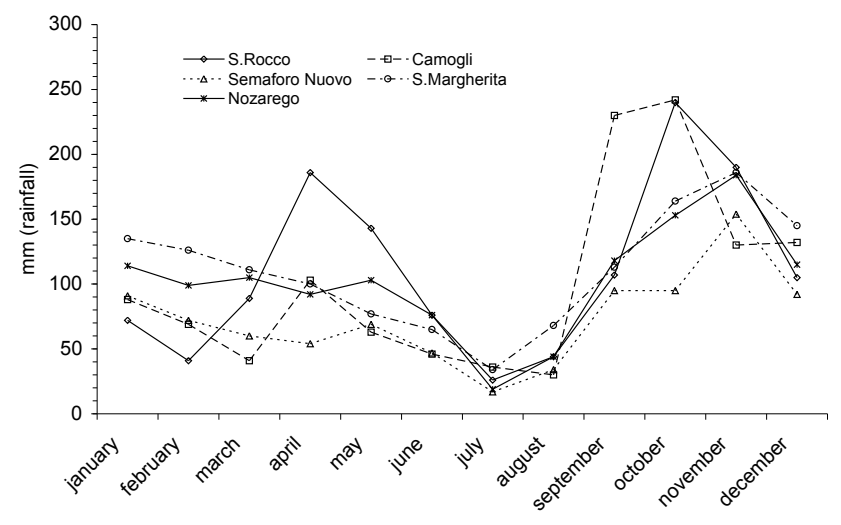

Fig. 2. Distribution of annual mean rainfall.

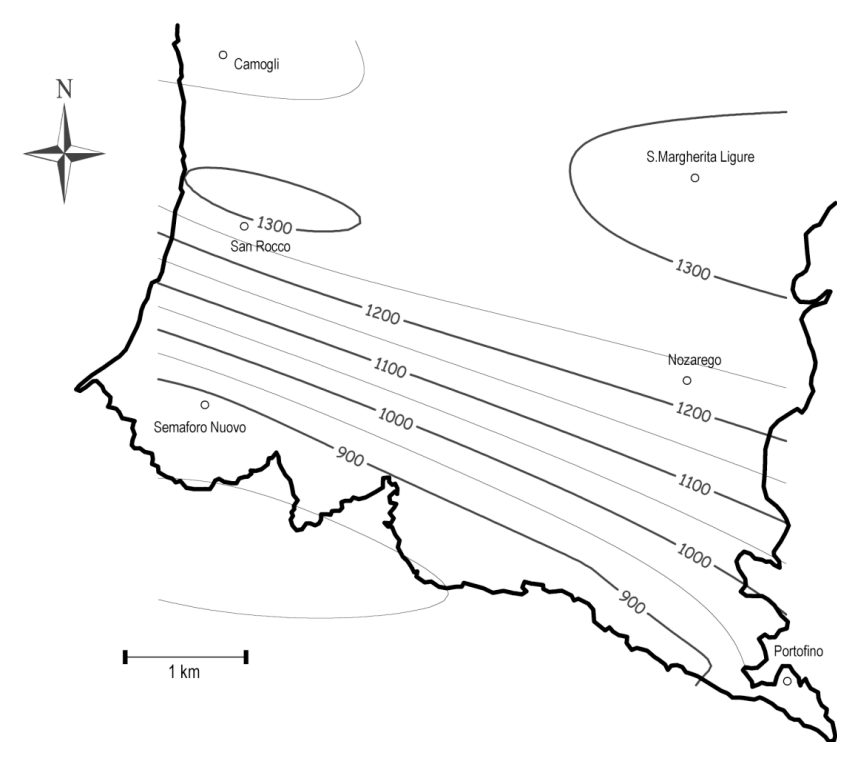

Fig. 3. Isohyet map with meteorological stations.

In general, maximum rainfall occurs in the autumn months, whereas the minimum takes place in the summer months (Fig. 2). Annual mean rainfall varies between 1000 and $1400 \mathrm{~mm}$ (Fig. 3) and the annual mean temperature ranges between 12 and $13^{\circ} \mathrm{C}$, reaching a $23-24^{\circ} \mathrm{C}$ peak in the summer and a low of $7-8^{\circ} \mathrm{C}$ in the winter.

Winds from the $\mathrm{S}$ are warm and saturated with water vapour after crossing wide expanses of sea. As they encounter and climb the natural barrier of the Promontory, the temperature decreases, causing condensation of large amounts of water, especially in the summer. This is largely due to the temperature gradient between the air and the rock discontinuities. This process supplies the numerous perennial springs, which are also found at high altitudes (Fig. 4). These springs have been used since historical times and are still used today by trekkers and visitors (Faccini et al., 2005).

The geological profile of the Promontory can be schematically indicated as Conglomerate overlying Flysch, along a 
contact with a SSW dip direction (Fig. 4). The Flysch, dating from the Upper Cretaceous - Paleocene (Corsi et al., 2001), is made up of marly limestone with thin interlayers of clayey shales, sandstones and calcarenites. The Conglomerate (Oligocene) consists of marly limestone pebbles ranging in diameter from centimetres to meters. Arenaceous elements are present to a minor extent, and other rock types, among which ophiolites and cherts, are even less frequent. The pebbles are embedded in a matrix that is generally calcareous-arenaceous, and sometimes quartzose or clayey.

The Conglomerate presents an average overall SSE dip direction in the western sector and SSW in the eastern sector, with a dip of $10^{\circ}-20^{\circ}$.

Interrelations between the geomorphological elements and tectonic lineations are observable, as follows. In addition to the faults delimiting the Promontory of Portofino, the drainage pattern and the watershed ridges, including both major and minor ones, all appear to be arranged on fracturing and fault lines, with the systems being oriented WNW-ESE, NNE-SSW, N-S and E-W.

\section{Methods}

The research was based on the following survey and dataprocessing phases: a) definition of general background information concerning the area or the tourist route, b) survey of the geomorphological hazard, c) survey of the structural morphological elements and the geoenvironmental elements that may affect trail vulnerability, d) definition of tourist vulnerability, and e) definition of possible risk scenarios.

Risk assessment takes into account factors relating to geomorphological hazard and factors relating to tourist vulnerability (Brandolini et al., 2004a). Three simplified classes of risk (i.e., Low, Medium, and High) are defined using a Geographic Information System (GIS).

The geomorphological hazard factors include all the natural processes that may affect hikers in any way along a trail (e.g. types of processes, states of activity, morphometric features, frequency, conditions of the bedrock). Besides the components regarding the trail considered as an infrastructure (e.g., characteristics and structure, state of preservation, steepness, exposure, and presence of protective devices such as barriers or railings), tourist vulnerability includes aspects relating to the vulnerability of hikers. These latter aspects may be subdivided according to the elements characterising the tourist influx (e.g. type and magnitude of the tourist influx, presence of infrastructures) and on the basis of the typology of visitors (e.g. sex, level of knowledge and awareness, physical and psychological preparation, equipment). Although this latter variable is very important for the identification of possible situations characterised by the interaction between natural hazards and visitors to the area, it was not taken into account in this specific case, owing to difficulty with insertion in the matrices used to define risk levels.

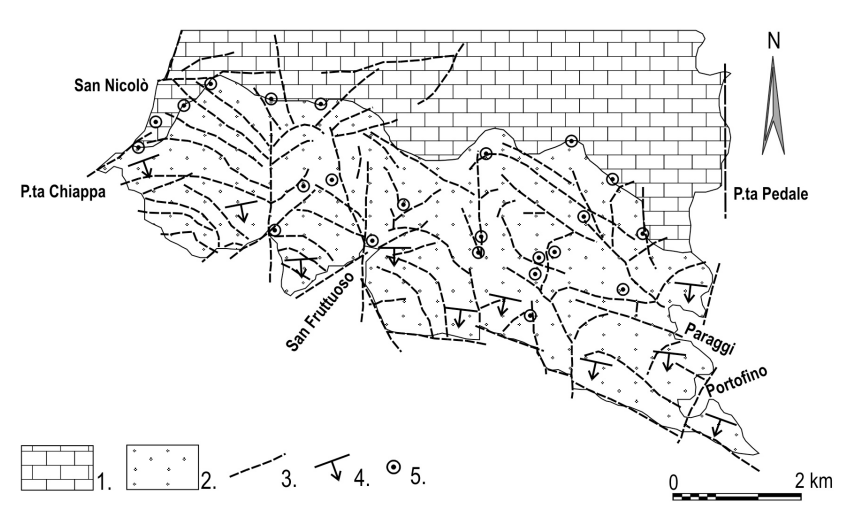

Fig. 4. Geological sketch map: 1. Flysch; 2. Conglomerate; 3. Fault or fracture; 4. Attitude; 5. Water spring.

\subsection{Geomorphological hazard}

Geomorphological dynamics on the promontory are characterized by landforms and processes triggered by gravity, running waters and by the action of the sea (Fig. 5).

Active landslides are prevalently concentrated on the western slope, between Camogli and San Rocco, where rockslide and rockfall phenomena are observable and affect residential areas, paths and other infrastructures (De Stefanis et al., 1984; Terranova, 1999; Brandolini et al., 2005). Additional mass movements are observable along the main watershed ridge zone, where they are aligned along the contact between the Conglomerate and the underlying Flysch. In this case, the landslides, which are essentially dormant, are determined by the geomechanical contrast between the formations described above. This leads to slowly developing lateral spread types of movement (Pietre Strette) or complex types of movement, a sort of combined rockfall and debris flow (Gave). Lastly, phenomena such as rockfalls and topples are frequent along the active cliff bordering the entire promontory. Near Santa Margherita Ligure, in particular, talus cones and scree slopes are created at the base, especially in the marly limestone, and they supply material to the gravellypebbly pocket beaches, often through steep ravines.

Landforms and processes due to running waters can be observed throughout the promontory. The debris flows in the western sector of the promontory are particularly important in terms of geomorphological dynamics (Schumm, 1994; De Chano and Butler, 2001). Moreover, colluvial deposits covering the contact between the Flysch and the Conglomerate are found in the upper portions of this slope. The deposits present thicknesses in the range of several meters in some cases and they have often been reworked into terraces for agricultural use. The drainage pattern on the southern slope is steep, very brief and with heavy rainfall, it causes marked transport of solids, resulting in serious geomorphological instability phenomena along the longitudinal profile. The flood of 1915 is one example of such an event, an event that led to 


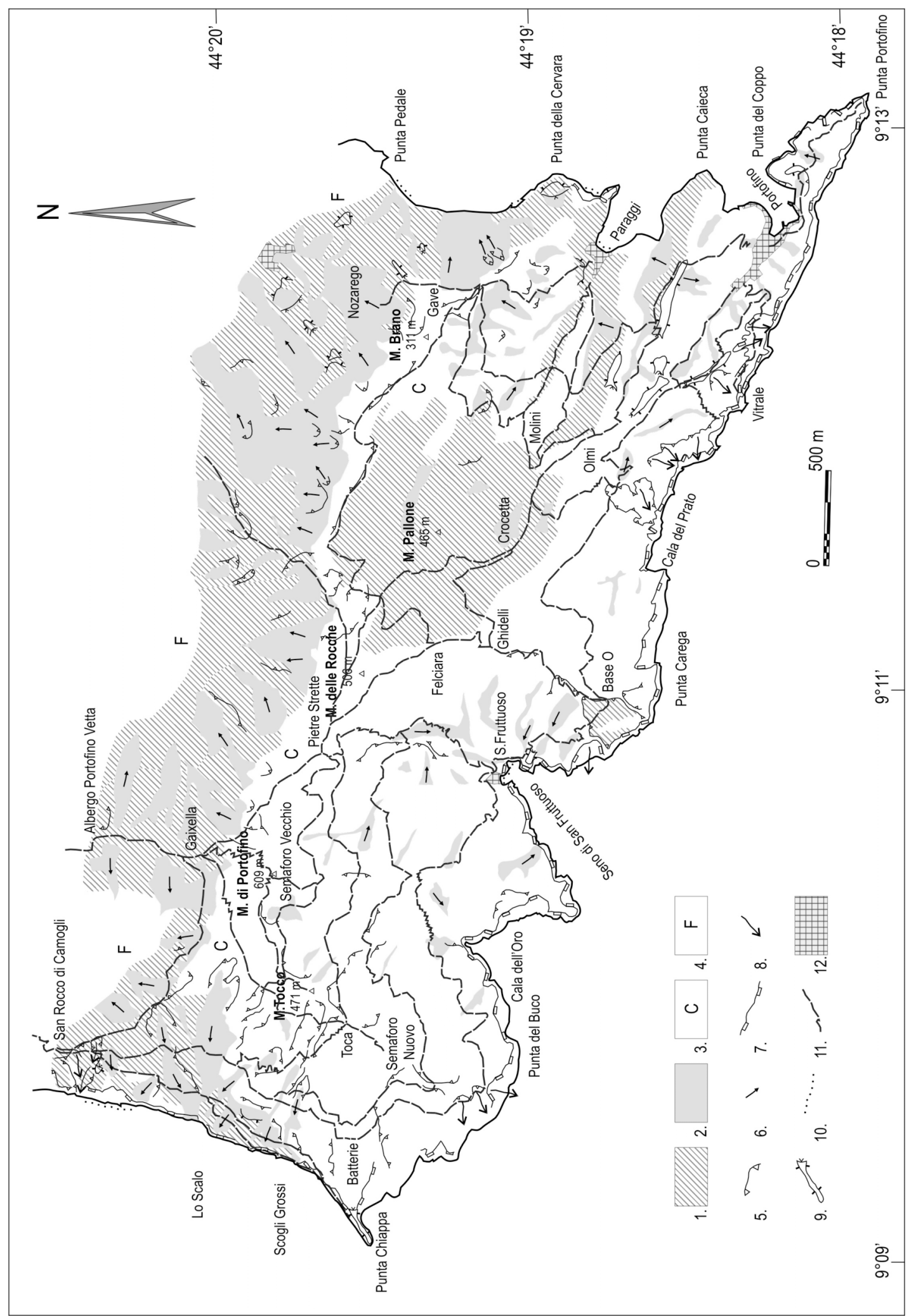

Fig. 5. Geomorphological map: 1. Colluvial deposit; 2. Landslide and debris cover; 3. Conglomerate; 4. Flysch; 5. Edge of degradational or landslide scarp; 6. Direction of movement; 7. Edge of scarp due to wave erosion; 8. Rock fall direction; 9. Planation surface; 10. Pocket beach; 11. Trail; 12. Build up area. 
rescue 1999-2004 (from CNSAS)

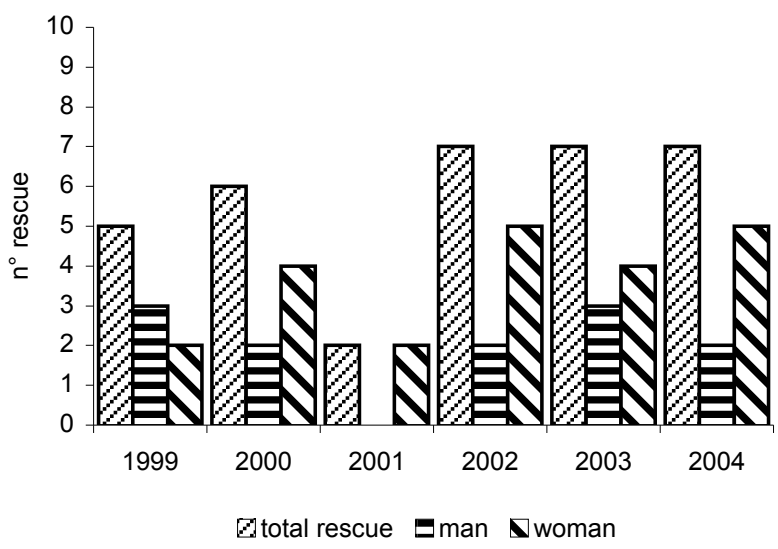

rescue months

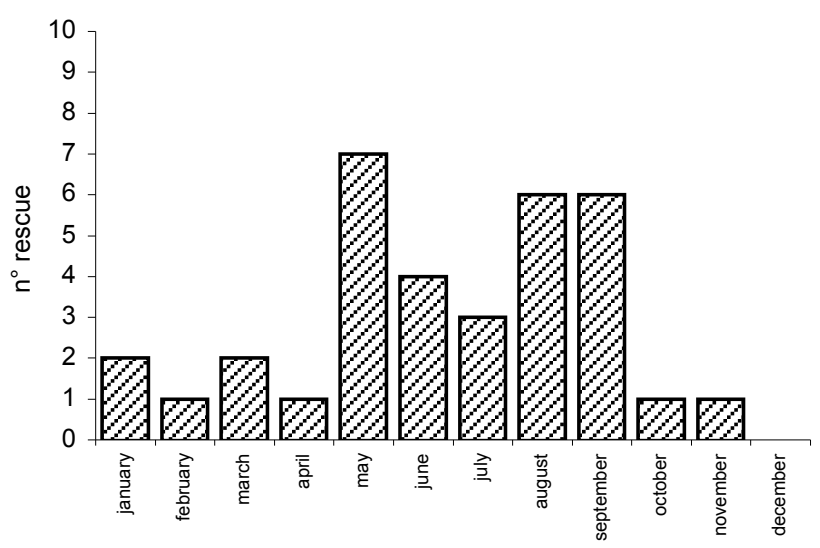

range of ages

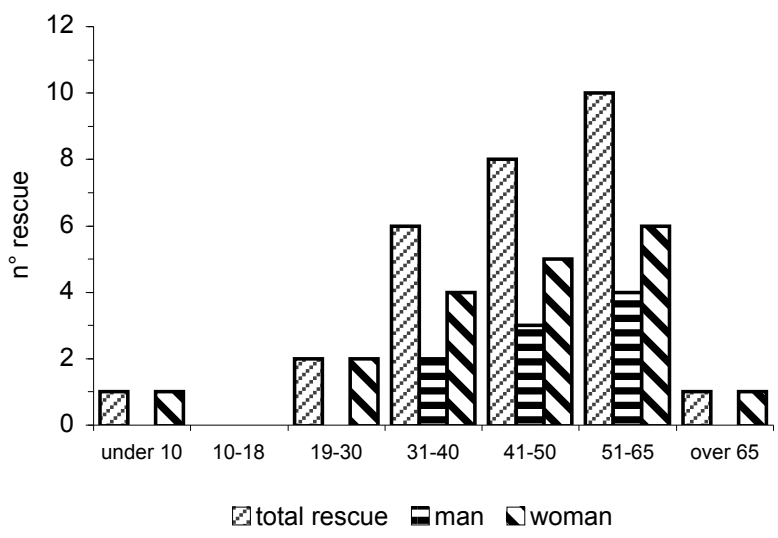

rescue days

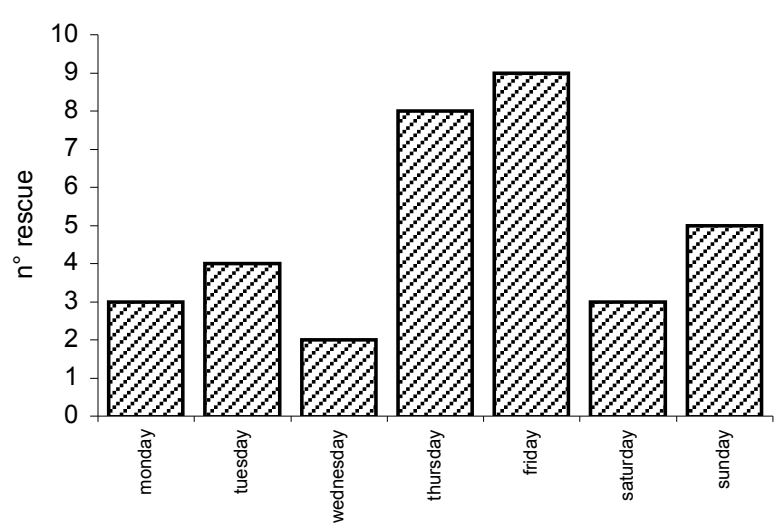

rescue tracks

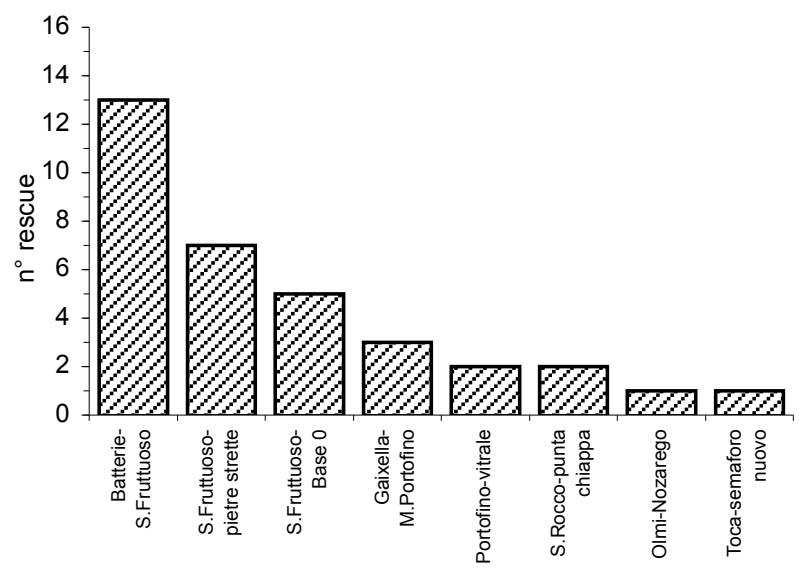

meteorologichal conditions

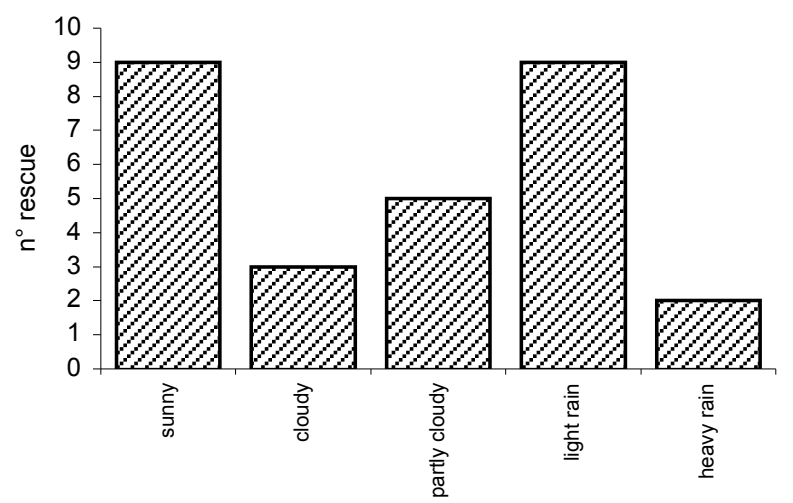

Fig. 6. Rescue data in the 1999-2004 period (source: Corpo Nazionale di Soccorso Alpino e Speleologico - C.N.S.A.S.).

the formation of San Fruttuoso beach, which had disappeared previously owing to marine erosion.

Along the coastal strip of the park, wave action takes on an important role as regards both the orientation of the coast- line with respect to dominant currents and in relation to the existing rock types and their geomechanical characteristics. As mentioned previously, erosion by wave motion has produced a cliff that reaches a height of over $25 \mathrm{~m}$. It is a very 


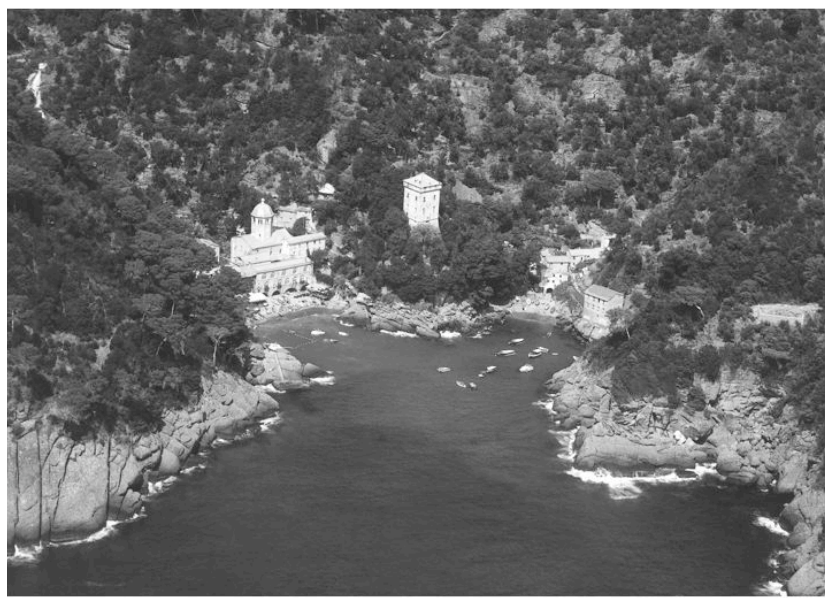

Fig. 7. Detail of San Fruttuoso bay, one of principal hiking/tourist destinations, with its two very popular small beaches.

characteristic feature of the southern slope with its typical series of promontories and inlets, among which we note the inlets of San Fruttuoso and Cala dell'Oro.

With its characteristic conglomeratic block, which projects further out than the surrounding coast, the promontory's particular coastal morphology is thought to be linked more to recent tectonic events than to other exogenetic agents. If the conglomeratic rock mass were not endowed with good intrinsic stability, marine erosion would surely have carved it out to a more pronounced degree. In fact, the slopes facing SSW are particularly exposed to wave cutting by rough seas with southwesterly currents, which carve them out frontally, and by those with southeasterly currents, which scour them.

\subsection{Trail and tourist vulnerability}

The promontory features a dense network of trails, with the routes covering more than $70 \mathrm{~km}$ on steep slopes, unwinding through a surface area slightly exceeding 1000 ha, and ranging in elevation from sea level up to more than $600 \mathrm{~m}$.

With departure points from San Rocco, Portofino Vetta, Nozarego and Portofino, which are the main park access locations, the park paths vary in length and levels of difficulty. These are mainly old flagstone or unpaved dirt mule tracks leading to the principal arrival points, Punta Chiappa, San Fruttuoso and Portofino, travelling through different morphoclimatic environments. The trails are conditioned by the morphology of the area. In particular, the trails on the southern slope leading to San Fruttuoso are steep, often with steps in the rock and narrow winding turns. There are sometimes difficult parts in ascent or descent, which make for a rather taxing hike.

As mentioned in the introduction, the data collected by the C.N.S.A.S. on rescue operations performed on the trails in the 1999-2004 period, show an average of 5-6 rescue ef- forts per year (Fig. 6). In a total of 28 operations, 9 men and 19 women were assisted; the age range was between 30 and 60 years. As expected, the data revealed a concentration of rescue operations between May and September, that is, the summer months when there is a major influx of tourists. The distribution of the rescue efforts, however, proved to be scattered throughout the days of the week.

The trails showing the largest number of incidents are those leading to the hamlet of San Fruttuoso (Fig. 7), that is, one trail in the western sector starting from Batterie, one in the northern sector starting from Pietre Strette, and another in the eastern sector starting from Base 0 , amounting to 13 , 7 and 5 rescue efforts respectively, or about $75 \%$ of the total.

A comparison between the weather conditions and the number of rescue operations revealed a multimodal distribution, although a substantial number of rescue operations took place when weather conditions were prevalently characterized by sunny weather or drizzle.

\section{Results}

As concerns geomorphological hazard, the Portofino Natural Park trails can be subdivided into 4 sectors according to their particular characteristics:

- the western sector, between Punta Chiappa and Camogli. The sector presents a continuous cliff that exceeds $25 \mathrm{~m}$ in height. Due to fracturing of the rock mass, the cliff is the source of rock falls and rock slides. The portions above the Poggio, Galletti and Mortola hamlets are characterized by significant active and inactive landslide scarps (De Stefanis et al., 1984; Brandolini et al., 2005);

- the eastern sector, between Punta Portofino and Santa Margherita Ligure. The sector presents a modelled cliff only in the Conglomerate, mainly between Punta del Coppo and Punta Portofino, and between Punta della Cervara and the Paraggi castle. Rock topple and rockfall phenomena may occur along the rock wall owing to localized alteration of the Conglomerate;

- the northern sector, situated along the Mortola, Mt. Portofino, Mt. delle Rocche, Mt. delle Croci di Nozarego and Mt. Brano alignment. The sector is characterized by the primary superposition of the Conglomerate on the Flysch. As mentioned previously, owing to the marked geomechanical contrast between the Formations, vast mass movements are observable. Some are active, among which the most well known are in the localities of Gave and Pietre Strette, in the upper part of the Fosso Magistrato and Santa Barbara basins. Along the contact, which is very evident owing to differences in steepness, there are continuous rockfalls and topples along the discontinuities with northward orientations; 


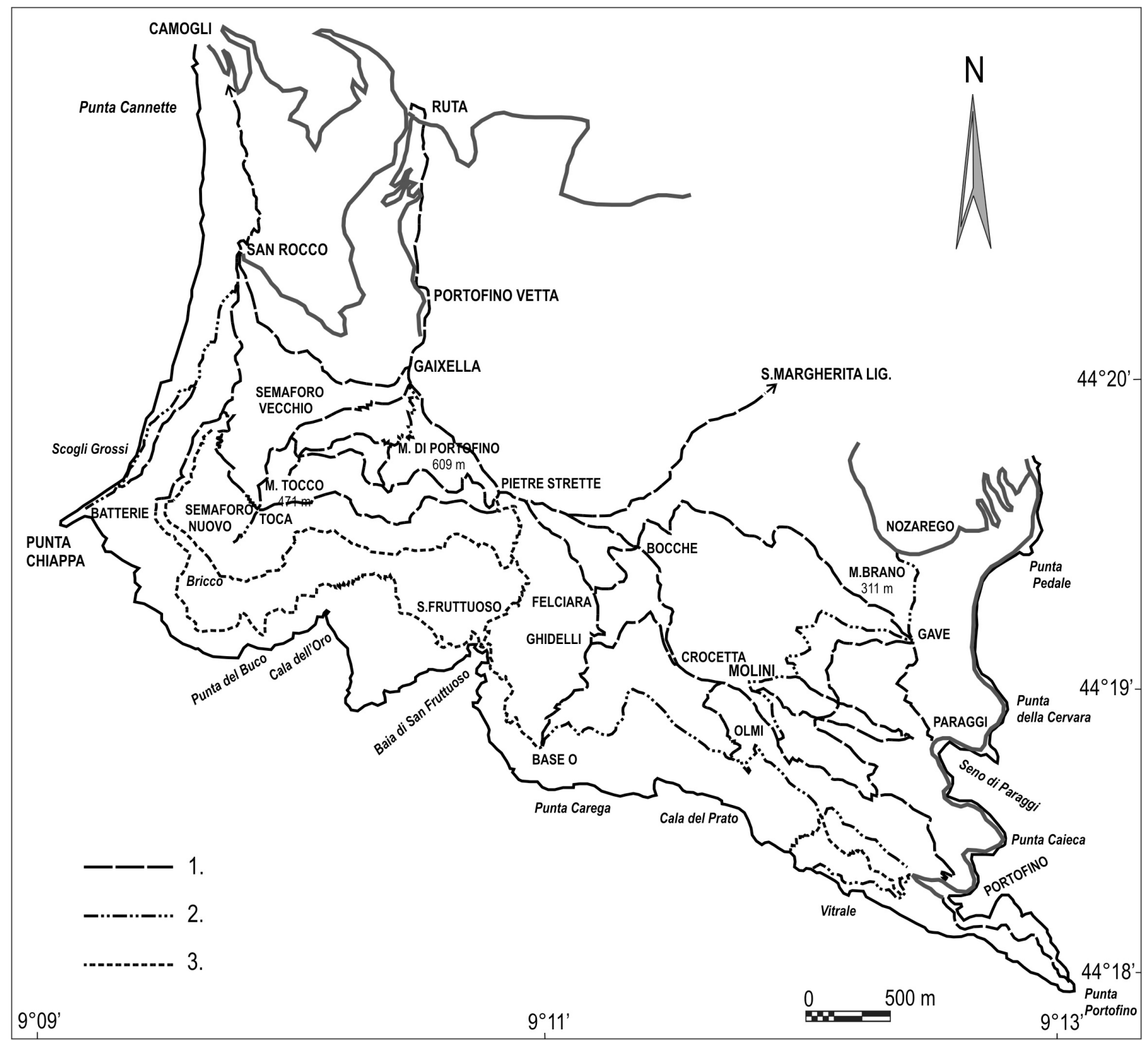

Fig. 8. Map of geomorphological risk along the trails in Portofino Park: 1. Low; 2. Medium; 3. High.

- the southern sector, between Punta Chiappa and Punta Portofino. The sector is characterized by a high cliff (over $100 \mathrm{~m}$ in height) modelled in the Conglomerate and broken up only by the Cala dell'Oro and San Fruttuoso inlets; the cliff represents a high-level geomorphological hazard. Potential kinematic mechanisms may occur in the rock mass owing to the discontinuities. They consist of planar sliding with wedge and toppling failure modes, constituting an evident hazard for hikers on the nature trail (Cevasco et al., 2004).

In terms of tourist vulnerability, the trails on the southern slope of the promontory, between Punta Chiappa to the W and Punta di Portofino to the E, witness the highest flow of tourists. However, these trails are also characterized by unfavourable infrastructural features. Generally speaking, they are very narrow trails, often without any form of protection, and they are poorly maintained. These hiking trails often lack any form of markings or signs providing information. Safety equipment is also lacking.

The crosscheck between geomorphological hazard and tourist vulnerability thus led to the definition of a risk scenario concerning critical situations in vast sectors of the trail network, but particularly on the southern slope of the promontory (Fig. 8). The risk was found to be high along all trails leading to San Fruttuoso, whereas it proved to be a medium-level risk along the trails leading to Portofino and always on the southern slope, which is steep and more exposed 

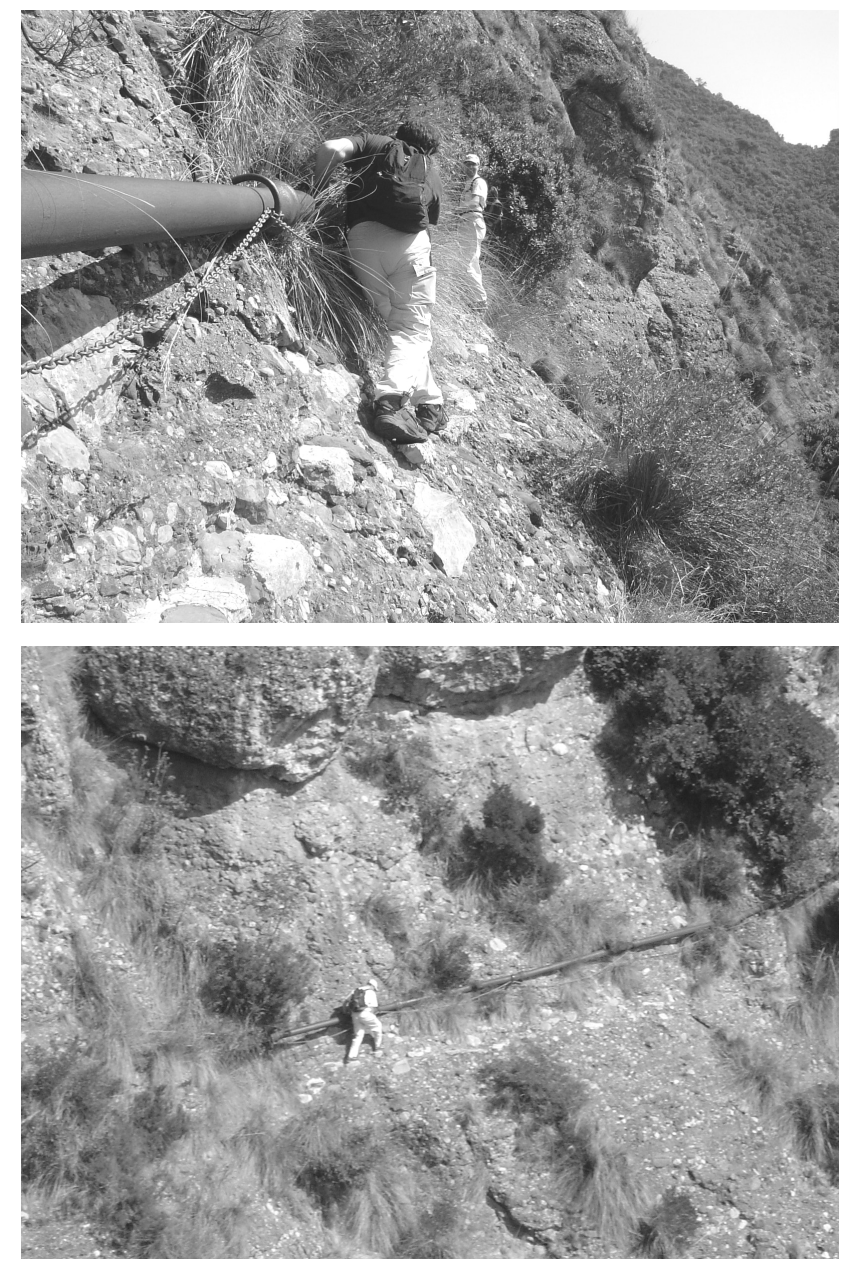

Fig. 9. The Caselle aqueduct trail (also known as "via dei Tubi") is one of the most hazardous trails in the western sector of Portofino Park.

to weather and sea conditions. The risk levels determined for the trails using this approach appear to be consistent with the objective findings obtained from statistical analysis of the rescue operations carried out in the park area.

The Caselle aqueduct trail, which is undoubtedly the most hazardous in terms of the geomorphological features in the study area, shows no recorded rescue operations in the period considered, as transit had long been banned due to numerous incidents in the past (Faccini et al., 2004). Today the trail is used only by trekkers who are physically fit, adequately equipped and accompanied by authorized Park Guides (Fig. 9).

\section{Conclusions}

The comparison and correlation of the geoenvironmental and tourist-related aspects described above clearly revealed vary- ing levels of geomorphological risk affecting the excursion routes in this park.

If adequately integrated with additional parameters, the proposed investigative model could be applied to other areas visited by tourists. The model could be adopted as an essential tool serving to mitigate the risk connected with physical and anthropic components. Such efforts could be aimed at creating a heightened awareness of the interaction between trekking/hiking activities and natural phenomena, and thus also of hazardous situations.

In conclusion, the data collected on this geomorphological environment could be made available to a wider public, ranging from the individual visitor, to Park Agency departments and staff, in the form of thematic geotourist or geoexcursion maps that are suitably condensed and simplified, and then generated and updated in the GIS (Geographical Information System) format. In turn, Park Agencies could utilize these maps as support for park area planning and management with the aim of safeguarding both the park and the park visitors, while also valorising the environment.

Acknowledgements. This work was carried out within the framework of the Ministry of Education, University and Research project "Geomorphological heritage as a resource for sustainable tourism" (COFIN 2004), National Coordinator: M. Panizza, and the local project of the Genoa University Research Unit on "Liguria's geomorphological heritage as a resource for sustainable tourism", Coordinator: M. X. Piccazzo. The authors wish to thank L. Sivori (C.N.S.A.S. - Tigullio Delegation) for the information supplied regarding rescue operations in the Park.

Edited by: T. Glade

Reviewed by: V. Agnesi and another referee

\section{References}

Bell, F. G.: Geological hazards: their assessment, avoidance and mitigation, London, New York, E \& FN Spon, 1999.

Brandolini, P., Farabollini, P., Motta, L., Motta, M., Pambianchi, G., Pelfini, M., and Piccazzo, M.: Geomorphologic hazards along tourist itineraries: some examples from Italy's territory, 32nd International Geological Congress, Florence, 20-28 August 2004a.

Brandolini, P., Motta, M., Pambianchi, G., Pelfini, M., and Piccazzo, M.: How to assess geomorphological risk in tourist areas. $32^{\circ}$ International Geological Congress, Florence 20-28 August 2004b.

Brandolini, P., Faccini, F., Robbiano, A., and Terranova, R.: Geomorphological hazard and monitoring activities in the western area of Portofino Promontory (Italy), 14th Meeting of the Association of European Geological Society, Turin, 19-23 September 2005.

Cevasco, A., Faccini, F., Nosengo, S., Olivari, F., and Robbiano, A.: Valutazioni sull'uso delle classificazioni geomeccaniche nell'analisi della stabilità dei versanti rocciosi: il caso del Promontorio di Portofino (Provincia di Genova), GEAM, 111, 31-38, 2004. 
Corsi, B., Elter, F. M., and Giammarino, S.: Structural fabric of the Antola unit (Riviera di Levante, Italy) and implications for its Alpine versus Apennine origin, Ophiolites, 26, 2001.

De Chano, L. M. and Butler, D. R.: Analysis of public perception of debris flow hazard, Disaster Prevention and Management, 10(4), 261-269, 2001.

De Stefanis, A., Marini, M., and Terranova, R.: Geomorfologia di aree campione della Liguria, C.N.R. "Progetto finalizzato alla conservazione del suolo", SELCA, Florence, 1984.

Dowling, R. and Newsome, D.: Geotourism, Elsevier, 352 p., 2005.

Faccini, F., Brandolini, P., Olivari, F., and Robbiano, A.: Geoturismo e cavità artificiali lungo il tracciato dell'acquedotto delle Caselle (Parco di Portofino), Proceedings of the 2nd Convegno Nazionale Geologia e Turismo, Bologna, 3-4 November 2004.

Faccini, F., Brandolini, P., Bonino, E., Piccazzo, M., Olivari, F., and Robbiano, A.: Phenomenes de condensation et sources perennes dans le Promontoire de Portofino (Italie), Volume de 18eme Colloque Association Internationale de Climatologie (AIC) "Climat Urbain, Ville et Architecture (à la mémoire de Roberto Rossetti, co-fondateur de l'AIC)", 2005.

Glade, T., Anderson, M. G., and Crozier, M. J.: Landslide hazard and risk, 807 p., Wiley, 2005.
Grecu, F., Comanescu, L., and Cruceru, N.: The perception of geomorphic risks in different territorial geosystems. Dynamic and applied signifiactions, in: Workshop on "Geomorphological sensitivity and system response", Camerino, Modena Apennines (Italy), 87-98, 2003.

Panizza, M.: Geomorphological Hazard Assessment and the Analysis of Geomorphological Risk, Intern Geomorph., 1, J. Wiley \& S., London, 1987.

Schumm, S. A.: Erroneous perceptions of fluvial hazards, Geomorphology, 10, 129-138, 1994.

Solana, M. C. and Kilburn, C. R. J.: Public awareness of landslide hazards: the Barranco de Tirajana, Gran Canaria, Spain, Geomorphology, 54(1-2), 39-48, 2003.

Swarbrooke, J., Beard, C., Leckie, S., and Pomfret, G.: Adventure tourism: the new frontier, Elsevier, 368 p., 2003.

Terranova, R.: Squilibri geomorfologici e rischi sulla costa alta rocciosa occidentale del Promontorio di Portofino (Liguria Orientale), Studi geografici e geologici in onore di S. Belloni, Università degli Studi di Milano e Milano Bicocca, 1999.

Varnes, D. J.: Landslide hazard zonation: a review of principles and practice, Natural hazards, 3, UNESCO. 63 p., 1984. 